\title{
Prediction of cover crack propagation in RC structures caused by corrosion
}

Leon Chernin

Research Associate, School of the Built Environment, Heriot-Watt University, Edinburgh, UK

Dimitri V. Val

Professor, School of the Built Environment, Heriot-Watt University, Edinburgh, UK

\section{Mark G. Stewart}

Professor and Director, Centre for Infrastructure Performance and Reliability, School of Engineering, University of Newcastle, Callaghan, NSW, Australia

The paper proposes a model relating the level of reinforcement corrosion (in terms of loss of rebar radius) with the width of corrosion-induced cracks. The model is developed using a simulation of the process of corrosion-induced crack opening by means of finite-element (FE) modelling. Concrete is treated as a linear elastic material, a vertical crack is introduced above a reinforcing bar and expansive behaviour of corrosion products is modelled using a thermal analogy. Corrosion products are divided into those that penetrate (dissipate) into cracks (no crack propagation) and those that cause crack opening. The amount of corrosion products penetrating into cracks at a specified crack width is evaluated using FE modelling and analyses of experimental results. It was found that a corrosion loss of $\mathbf{0 . 1 - 0 . 4 ~ m m ~ d i s s i p a t e d ~ i n t o ~ t h e ~ c r a c k s ~ w h e n ~ t h e ~ c r a c k ~ w i d t h ~ w a s ~} \mathbf{1 . 0} \mathrm{mm}$. The influence of geometric parameters such as rebar diameter, spacing and location, and thickness of top and edge concrete covers were investigated. The limits of applicability of the proposed relationships were established using non-linear FE modelling.

\section{Introduction}

Corrosion of reinforcing steel in concrete is the main cause of deterioration of reinforced concrete (RC) structures, which initially manifests itself in corrosion-induced cracking of the concrete cover. The cracks immediately after initiation are small and do not have a significant effect on structural performance. However, they grow as corrosion propagates and eventually lead to serviceability failure of the structure. Thus, predicting the behaviour of RC structures after crack initiation (i.e. predicting crack growth and the time when cracks become unacceptable due to serviceability requirements) is important for selecting efficient maintenance and repair strategies (Li et al., 2004; Mullard and Stewart, 2009; Val, 2007). Moreover, in order to assess the condition of an existing RC structure, knowledge of the amount of reinforcing steel lost due to corrosion, if the latter is present, is essential. While this amount cannot be measured directly without removing the reinforcement from the structure, it can be estimated indirectly using a model that relates the width of a corrosion-induced crack to the loss of cross-sectional area of a reinforcing bar (e.g. Thoft-Christensen, 2005; Vidal et al., 2004). Many empirical, analytical and numerical models for prediction of crack width have been developed (e.g. Li et al., 2006; Maruyama et al., 1989; Rodriguez et al., 1996; Thoft-Christensen, 2005; Thoft-Christensen et al., 2008; Vu et al., 2005), and a critical overview of these models is presented in this paper, including a comparison of several empirical models with the results of accelerated corrosion tests on RC slabs (Mullard and
Stewart, 2011). Since the results of these tests are also used in this paper to calibrate numerically derived new models, the tests are also briefly described.

Although experimental studies are essential for studying corrosion-induced cracking of a concrete cover, it is not feasible with their help alone (due to time and cost constraints) to examine the influence of variation of a large number of parameters such as thickness of the concrete cover, diameter and location of a reinforcing bar, concrete properties, etc. on this process. The present paper concentrates on studying crack propagation (i.e. the growth of crack width after the crack reaches the surface of a RC structure) using finite-element (FE) simulations, with the aim of deriving formulae relating corrosion penetration to crack width. The expansive behaviour of corrosion products is simulated using a thermal analogy (i.e. by thermal expansion of a corroding reinforcing bar). Initially, two FE models were compared:

(a) a non-linear FE model in which the concrete behaviour in tension is described by the cohesive crack model (Hillerborg et al., 1976) so that the model is capable of simulating concrete cracking

(b) a linear FE model in which a vertical crack above a corroding reinforcing bar is introduced by inclusion of a very thin gap into the concrete cover.

Differences between the predictions of crack width yielded by the 
two models were insignificant, so the simpler linear model was chosen for further study.

Values of the crack width predicted by the FE models are also compared with test results. The comparison shows that the FE models significantly overestimate the crack width. The main reason for this discrepancy is a known phenomenon - some corrosion products forming near a corroding reinforcing bar penetrate into concrete pores and cracks and, therefore, do not contribute to the pressure exerted on the concrete surrounding the rebar and, subsequently, to crack opening (e.g. Val et al., 2009). Therefore, estimating the amount of corrosion products penetrating into concrete pores and cracks is very important for the prediction of crack width.

It is assumed in the present study that no corrosion products penetrate into concrete pores. This assumption is supported by experimental evidence (Wong et al., 2010) showing that a substantial part of corrosion products after crack initiation is located in large cracks rather than in concrete pores. Therefore, this simplification in the problem formulation leads to an insignificant overestimation of the amount of corrosion products penetrating into concrete cracks. A number of other reasons for the difference between the FE model and experimental results arise due to the use of a linear FE model with an introduced crack. These reasons are listed and discussed in the paper. A method for evaluating the discrepancy between FE results and test data is developed. This is done by assuming that the penetration of corrosion products into concrete cracks is the main cause of differences between the results of FE simulations and the experimental data reported by Mullard and Stewart (2011). Relationships between the corrosion penetration corresponding to the part of corrosion products diffusing into cracks and the crack width are established for different locations of a reinforcing bar.

The results of FE simulations are then employed to derive relationships between corrosion penetration corresponding to the part of corrosion products that contribute to crack opening and the crack width. The influence of parameters such as the diameter of a reinforcing bar, thickness of the top and edge concrete covers, and the spacing between and location of reinforcing bars on crack width growth is taken into account. The relationships are derived using multi-parametric regression analysis. Finally, the limits of applicability of the derived relationships are established using the non-linear FE model, which is capable of simulating different types of cover failure (e.g. spalling of the section corner and cover delamination). It should be noted that the derived relationships are more suitable for cases when more or less uniform corrosion of reinforcement is expected. The influence of non-uniform corrosion on cracking of the concrete cover is considered, for example, by Jang and Oh (2010).

\section{Overview of existing models}

Models for prediction of corrosion-induced crack opening in a concrete cover can broadly be divided into three main groups: empirical, analytical and numerical models. Crack opening due to corrosion has been investigated in a number of experimental studies. Most of them involved accelerated corrosion tests with impressed current that provided data on crack growth depending on the amount of corrosion (e.g., Alonso et al., 1998; Andrade et al., 1993; Cabrera, 1996; Mangat and Elgarf, 1999; Maruyama et al., 1989; Rodriguez et al., 1996; Vu et al., 2005). Empirical models are based on analysis of experimental results, including determination of the major parameters controlling the width of a corrosion-induced crack (Alonso et al., 1998; Rodriguez et al., 1996; Vidal et al., 2004; Zhang et al., 2010). Regression analysis is then used to derive a formula relating these parameters to a corrosion level corresponding to a certain crack width. The major parameters normally considered in the empirical models are geometrical properties (e.g. the thickness of concrete cover $c$ and diameter of reinforcing bar $d$ ) and concrete properties (e.g. water/ cement ratio and the splitting tensile strength of concrete $f_{\mathrm{ct}}$ ).

A number of models simply relate the crack width with corrosion penetration. Andrade et al. (1993) suggested that for $c / d>2$, a corrosion penetration of $x=0.2 \mathrm{~mm}$ led to a crack width equal to $0.3 \mathrm{~mm}$. Alonso et al. (1998) reported that for $c / d>2$, a corrosion penetration of $x=0 \cdot 1-0 \cdot 2 \mathrm{~mm}$ caused a crack width $w=0.3 \mathrm{~mm}$, while $x=0.3 \mathrm{~mm}$ corresponded to $w=1.0 \mathrm{~mm}$. The authors noted that the scatter of the obtained crack widths was very high due to variable penetration of corrosion products into developing cracks.

Rodriguez et al. (1996) derived a linear relationship to estimate crack width $w$ (in $\mathrm{mm}$ ) on the basis of data from accelerated corrosion tests on RC beams:

$$
\text { 1. } w=0.05+\beta\left[x-\left(83 \cdot 8+7 \cdot 4 c / d-22 \cdot 6 f_{\mathrm{ct}}\right)\right]
$$

where $x$ is the corrosion penetration in $\mu \mathrm{m}$ and $f_{\mathrm{ct}}$ is in MPa. Different values of the slope, $\beta$, were suggested depending on the rebar location: 0.01 for top cast bars and 0.0125 for bottom cast bars. A lower value of the slope for the top cast reinforcement reflects the fact that concrete near the top is more porous and allows more diffusion of corrosion products. This approach was also adopted by DuraCrete (2000).

Vidal et al. (2004) reported results linking the amount of corrosion with the width of cover cracks obtained in two beams naturally corroded in a saline environment for 14 and 17 years. A linear relationship between the amount of corrosion and the crack width was observed:

$$
\text { 2. } \quad w=0 \cdot 0575\left(\Delta A_{\text {steel }}-\Delta A_{\text {steel,cr }}\right)
$$

where $\Delta A_{\text {steel,cr }}$ is the consumed part of the rebar cross-section (in $\mathrm{mm}^{2}$ ) at initiation of a cover crack and $\Delta A_{\text {steel }}$ is the part of rebar 
cross-section consumed by corrosion (in $\mathrm{mm}^{2}$ ), which is given by:

$$
\text { 3. } \Delta A_{\text {steel }}=0 \cdot 25 \pi \alpha_{\mathrm{v}} x\left(2 d-\alpha_{\mathrm{v}} x\right)
$$

where $\alpha_{\mathrm{v}}(=2)$ is the volumetric expansion ratio of corrosion products and $d$ is in $\mathrm{mm} . \Delta A_{\text {steel,cr }}$ is calculated from:

4.

$$
\Delta A_{\text {steel,cr }}=A_{\mathrm{s}}\left[1-\left(1-0 \cdot 001 \alpha_{\mathrm{v}} \frac{7 \cdot 53+9 \cdot 32 c / d}{d}\right)^{2}\right]
$$

where $A_{\mathrm{s}}$ is the cross-section of an intact reinforcing bar $\left(\mathrm{mm}^{2}\right)$. The same research group presented results of a long-term test on a RC beam stored in a chloride environment for 23 years (Zhang et al., 2010). Zhang et al. used the average loss of rebar crosssection, $\Delta A_{\mathrm{sm}}$, as a governing parameter in the evaluation of crack width. A linear relationship between $\Delta A_{\mathrm{sm}}$ (in $\mathrm{mm}^{2}$ ) and $w$ (in $\mathrm{mm}$ ) was suggested:

$$
\text { 5. } \quad w=0 \cdot 1916 \Delta A_{\mathrm{sm}}+0 \cdot 164
$$

Muñoz et al. (2007) carried out tests on two RC elements with added chlorides exposed to Madrid's atmosphere for more than 15 years. Using the test data, the authors derived two similar relationships for calculation of crack width. In the first, $w$ is assumed to depend linearly on $x$ and inversely proportional to $d$ :

$$
\text { 6. } w=k_{1} \frac{x}{d / 2}
$$

while in the second relationship, $w$ depends on $x$ divided by the c/d ratio

$$
\text { 7. } w=k_{2} \frac{x}{c / d}
$$

where $w, x$ and $d$ are in $\mathrm{mm}$ and $k_{1}$ and $k_{2}$ are dimensionless proportionality coefficients. Muñoz et al. (2007) used their own test results as well as already published experimental data to evaluate $k_{1}$ and $k_{2}$. However, a very wide scatter of values of $k_{1}$ and $k_{2}$ was obtained and clear guidelines were provided only for Madrid's atmosphere.

The described empirical models can be used for evaluation of the time since corrosion initiation until a crack reaches a certain width $w, t_{\mathrm{w}}$, of course, under the condition that the corrosion rate is known and constant with time (or the time-dependent nature of the corrosion rate is known). If a model relates crack width with the total amount of corrosion, this can be done by simply dividing the corrosion penetration by the corrosion rate (or using Faraday's law of electrolysis when the corrosion rate is given in terms of the corrosion current density). If a model distinguishes between the amount of corrosion leading to crack initiation and the total amount of corrosion (e.g. Vidal et al., 2004), then $t_{\mathrm{w}}$ needs to be presented as a sum of the time from corrosion initiation to cover cracking (crack initiation period), $t_{\text {init }}$, and the time since cover cracking until the crack width reaches $w$ (crack opening period), $t_{\text {op: }}$ :

8. $t_{\mathrm{w}}=t_{\text {init }}+t_{\mathrm{op}}$

where $t_{\text {init }}$ can be estimated using a model for predicting crack initiation.

Another group of models relates crack width directly or indirectly to the time needed for the crack to reach a certain width. Vu et al. (2005) developed a non-linear relationship for evaluation of $t_{\mathrm{op}}$ depending on 'concrete quality', defined as the ratio between the concrete cover $c$ and the water/cement ratio (w/c). The relationship included a number of empirical coefficients estimated by regression analysis of experimental data. The experimental time $t_{\mathrm{op}(\exp )}$ (in hours) needed for a crack to reach a certain width was expressed as:

9. $t_{\mathrm{op}(\exp )}=\lambda\left(\frac{c}{\mathrm{w} / \mathrm{c}}\right)^{\theta}$

where $\lambda$ and $\theta$ are empirical constants, which were given for crack widths of $0.3,0.5$ and $1.0 \mathrm{~mm}$. Based on existing experimental evidence (Alonso et al., 1998; El Maaddawy and Soudki, 2003; Saifullah and Clark, 1994), Vu et al. (2005) suggested extrapolating crack opening times obtained from accelerated corrosion tests to crack opening times at the lower corrosion rates observed in real structures, $t_{\mathrm{op}(\text { real })}$ :

10. $t_{\mathrm{op}(\mathrm{real})}=k_{\mathrm{R}} \frac{i_{\text {corr (exp) }}}{i_{\text {corr(real })}} t_{\mathrm{op}(\exp )}$

where $i_{\text {corr(exp) }}$ is the experimental corrosion rate from accelerated corrosion tests, $i_{\text {corr(real) }}$ is the corrosion rate developed in the real $\mathrm{RC}$ element and $k_{\mathrm{R}}$ is the rate of loading correction factor, which was found using regression analysis of experimental data (Alonso et al., 1998; El Maaddawy and Soudki, 2003; Saifullah and Clark, 1994) for the range $0 \leqslant i_{\text {corr(exp) }} / i_{\text {corr(real) }} \leqslant 100 \mu \mathrm{A} / \mathrm{cm}^{2}$ :

11. $k_{\mathrm{R}} \approx 0 \cdot 95\left[\exp \left(-\frac{0 \cdot 3 i_{\text {corr(exp) }}}{i_{\text {corr(real })}}\right)-\frac{i_{\text {corr(exp })}}{2500 i_{\text {corr(real })}}+0 \cdot 3\right]$

where $k_{\mathrm{R}} \geqslant 0 \cdot 25$. 
Mullard and Stewart (2011) provided additional data that confirmed Equation 11 and developed a linear relationship between the time since crack initiation (in hours) and crack width, where the rate of crack opening depends non-linearly on $c / d$ and $f_{\mathrm{ct}}$ :

$$
\text { 12. } t_{\mathrm{op}(\exp )}=\frac{w-w_{\mathrm{i}}}{k_{\mathrm{c}} \times 0.0008 \exp \left[-1 \cdot 7 c /\left(d f_{\mathrm{ct}}\right)\right]}
$$

where $w_{\mathrm{i}}$ is the crack width at the time of crack initiation, which can be taken as $0.05 \mathrm{~mm}$ - a crack visible to a naked eye (Andrade et al., 1993) - and $k_{\mathrm{c}}$ is a confinement correction factor that takes into account the concrete confinement around a reinforcing bar. Values of $k_{\mathrm{c}}$ were separately estimated for reinforcing bars located in top corners and along the top sides of RC slabs using a limited set of experimental data. Equation 12 was derived for $0.1 \leqslant c /\left(d f_{\mathrm{ct}}\right) \leqslant 1.0$ and $w \leqslant 1.0 \mathrm{~mm}$. It is necessary to note that both Equations 9 and 12 were obtained using experimental data corrected to the nominal corrosion rate $i_{\text {corr(exp) }}=100 \mu \mathrm{A} / \mathrm{cm}^{2}$.

A comparison of the crack widths yielded by empirical models (Rodriguez et al., 1996; Vidal et al., 2004; Vu et al., 2005; Zhang et al., 2010) with those observed in the accelerated corrosion tests carried out by Mullard and Stewart (2011) is shown in Figure 1. In the comparison, the volumetric expansion ratio of corrosion products, $\alpha_{\mathrm{v}}$, was set equal to 3 in accordance with the work of Suda et al. (1993). The empirical models from Rodriguez et al. (1996) and Vu et al. (2005) and the experimental data of Mullard and Stewart (2011) used for the comparison were derived using accelerated corrosion tests (corrosion rates of $100-200 \mu \mathrm{A} / \mathrm{cm}^{2}$ ). Vidal et al. (2004) and Zhang et al. (2010) derived their models using tests with natural corrosion (corrosion rates of $1-3 \mu \mathrm{A} / \mathrm{cm}^{2}$ ). In order to ensure consistency of the model comparison, the Vidal et al. (2004) and Zhang et al. (2010) models were adjusted to the high corrosion rates in the tests of Mullard and Stewart (2011) using the method developed by Vu et al. (2005). The relationship between corrosion penetration obtained under low (real) and high (experimental) corrosion rates and corresponding to the same crack width is:

13. $x_{\mathrm{op}(\text { real })}=k_{\mathrm{R}} x_{\mathrm{op}(\exp )}$

Substitution of Equation 13 into Equation 3 enables the determi-

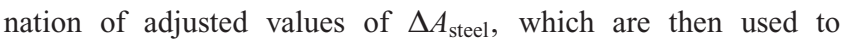
calculate the crack width by the Vidal et al. (2004) and Zhang et al. (2010) models.

The model proposed by Mullard and Stewart (2011) does not appear in the comparison because it was derived using the same experimental data. The analysis was performed for reinforcing bars at corners (Figure 1(a)) and in the middle (Figure 1(b)) of RC slab specimens (Mullard and Stewart, 2011). Figure 1 shows that, compared with the test results, the Vidal et al. (2004) model underestimates crack width, while the other empirical models lead, in a number of cases, to significant overestimation. It is impossible to conclude with certainty which of the compared empirical models provides the best agreement with the experimental data, but this comparison illustrates the limitations of the empirical models and their strong dependency on usually limited test data (i.e. geometrical, material and environmental parameters) used for their derivation.

A number of studies used analytical modelling for prediction of crack width in a concrete cover. Maruyama et al. (1989) suggested a method based on simple considerations of the rigid body movements of parts of the concrete between cracks. It was supported by the assumption that, since cracking of concrete cover, crack width grows almost linearly with corrosion of a reinforcing bar. The model took into account a number of geometrical parameters such as thickness of the concrete cover, the rebar diameter and its corrosion-induced increase, and the length and angle of a secondary crack. The authors carried out a series of tests on concrete cubes reinforced with a single corroded bar in order to investigate the influence of cross-sectional dimensions and crack patterns on the length and angle of a secondary crack. However, no clear guidelines were provided for evaluation of these parameters. Cabrera (1996) extended the approach of Maruyama et al. (1989) by including additional parameters such as thickness of the side concrete cover and the angle between main and secondary cracks. An apparent disadvantage of this analytical method is its a priori selection of the pattern of cracks developed in a RC section. It addition, the use of this method cannot be extended beyond a symmetric RC section reinforced by a single bar without further experimental research.

Thoft-Christensen (2001) developed a geometrical approach assuming that the crack width was linearly proportional to the level of rebar corrosion. An increase in the volume of a single trapezoidal crack was modelled as equal to an increase in the volume occupied by corrosion products. This suggests that corrosion products fully fill a crack (or cracks) immediately after its (their) initiation.

Li et al. (2006) used a method originally developed for analysis of corrosion-induced crack initiation to model crack opening. The method is based on treating the concrete around a corroding reinforcing bar as a hollow thick-walled cylinder with the wall thickness equal to the thickness of the concrete cover, which is subjected to uniform internal pressure. Complete fracture of the cylinder wall is taken into account by reducing its tangential stiffness. The authors solved the problem in a plane stress formulation, even though plane strain formulation is more suitable for this case. In addition, the model is unable to take into account the influence of different locations of a corroding reinforcing bar in a RC section.

A number of numerical studies of corrosion-induced cracking in 

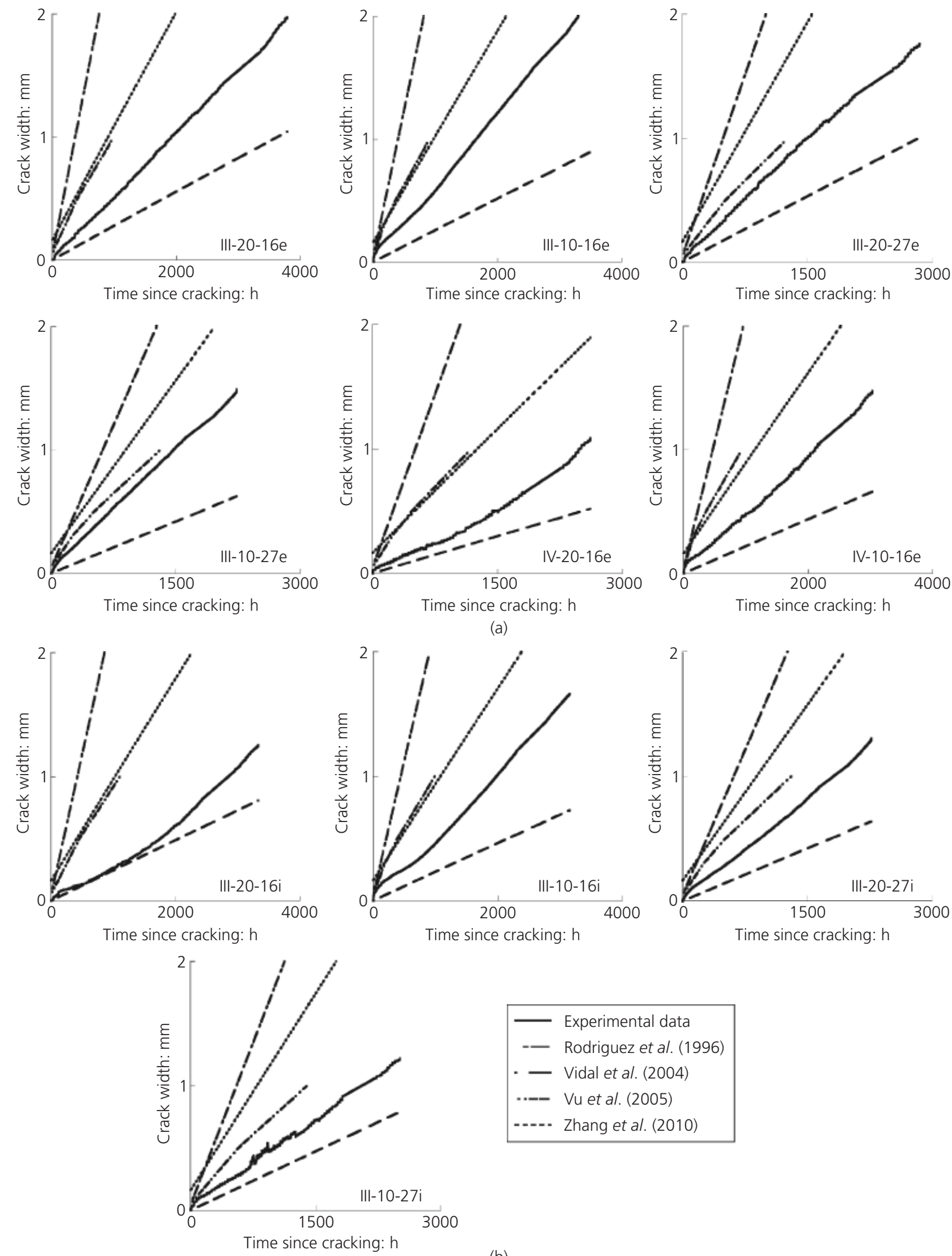

Figure 1. Prediction of crack opening above (a) corner bars and (b) middle bars for specimens from Mullard and Stewart (2011) 
concrete have been carried out (e.g. Dagher and Kulendran, 1992; Hansen and Saouma, 1999; Molina et al., 1993; Toongoenthong and Maekawa, 2005). However, only a few studies have concentrated on crack opening and its dependence on corrosion level. Thoft-Christensen (2005) developed a two-dimensional (2D) FE model of a cracked RC cross-section with a single reinforcing bar. Different combinations of concrete cover and rebar diameter were analysed, and a linear relationship between the increase in crack width and the corresponding corrosion penetration was established. The expansive behaviour of corrosion products was modelled by applying uniform internal pressure. The concrete was treated as a linear elastic material. The crack was modelled by introducing a $0 \cdot 1 \mathrm{~mm}$ gap into the concrete cover. In subsequent work, Thoft-Christensen et al. (2008) extended the approach to a 3D FE model of a part of a RC beam with a single reinforcing bar. It should be noted that simulation of the expansive behaviour of corrosion products by applying internal uniform pressure is only correct when the problem under consideration is axisymmetric (e.g. a single corroding rebar in the middle of a circular or square cross-section); in other cases it leads to an incorrect stress-strain state in the concrete around a corroding rebar. Val and Stewart (2009) give a full review of crack initiation and propagation models.

Most of the numerical models showed significant overestimation of crack width compared with experimental results. This was explained by penetration of a part of corrosion products into forming cracks so that these corrosion products did not contribute to the pressure between a corroding reinforcing bar and the surrounding concrete and, subsequently, to crack opening (Molina et al., 1993). Thus, in a number of studies it was assumed that corrosion products fully filled a crack immediately after its initiation (e.g. Molina et al., 1993; Thoft-Christensen, 2005). However, Val et al. (2009) showed that this assumption overestimated the amount of corrosion products penetrating into cracks and that corrosion products filled cracks gradually over time.

It should also be noted that most of the existing models were developed for the evaluation of crack width. However, in the assessment of a corroded RC structure, the crack width is a measurable value while the level of rebar corrosion is what needs to be assessed. Thus, one of the aims of the present study is to derive relationships between crack width and corrosion penetration that can easily be used either way - to estimate crack width when the corrosion penetration is known or to predict the latter when the crack width is known.

\section{Experimental crack opening data}

Four series of tests comprising ten RC slab specimens were prepared to investigate the relative influence of concrete cover, concrete strength, bar diameter, bar confinement and corrosion rate on the rate of crack propagation. The specimens were $500 \times 1000 \times 250 \mathrm{~mm}$ thick rectangular slabs, each containing four (equally spaced) mild steel reinforcing bars. A summary of the experimental parameters for all series is shown in Table 1, where specimen notation is top cover $(\mathrm{mm})$-bar diameter $(\mathrm{mm})$, followed by $i$ or $e$ for internal or external reinforcement, respectively. The specimens were moist-cured for 28 days before current was applied to begin accelerated corrosion. Standard test cylinders were tested at 28 days to determine the mean compressive and tensile (splitting) strengths.

The cement used was ordinary Portland cement and the concrete was delivered in ready-mix agitator trucks. Three percent calcium chloride $\left(\mathrm{CaCl}_{2}\right)$ by weight of cement was added to the concrete mix in order to induce corrosion along the length of the reinforcing bars. A current density of $100 \mu \mathrm{A} / \mathrm{cm}^{2}$ was chosen as the accelerated corrosion rate. The soffit of the specimen was immersed in a $5 \%$ sodium chloride $(\mathrm{NaCl})$ solution. The accelerated corrosion process was achieved by applying a constant electrical current to the bars via a current regulator. The steel reinforcing bar acts as the anode, the stainless steel plate submerged in the $\mathrm{NaCl}$ solution acts as the cathode and the pore fluid in the concrete acts as the electrolyte. Testing was terminated when specimens had crack widths in excess of $1.0 \mathrm{~mm}$.

Crack initiation was recorded to have occurred when the first visual cracking was observed on the top surface of the RC specimens. Cracks were observed through a microscope with a graduated scale of $0.02 \mathrm{~mm}$ increments. Immediately after crack initiation was observed, linear potentiometer displacement transducers were glued to bridge over the crack so as to record the rate of crack propagation. The time to crack initiation was generally observed within a few days for all specimens and the cracks appeared in various locations over the reinforcing bar. These cracks then began to propagate and join together to form a continuous longitudinal crack in the concrete cover approximately parallel to the reinforcing bar. Results of the tests are shown in Figure 2.

At the completion of accelerated testing, samples of the corrosion products were collected from the surface of the reinforcing bars and an x-ray diffraction analysis was conducted to determine the composition of the corrosion products. The volumetric expansion ratio of rust was $2 \cdot 74$. This compares well with other estimates found in the literature, which range from $2 \cdot 0$ to $3 \cdot 2$. Since the volumetric expansion ratios for accelerated testing compare reasonably well with values estimated from non-accelerated corrosion, the accelerated testing described here seems to simulate the natural corrosion environment realistically. More details on the experiment and the results are reported by Mullard and Stewart (2011).

\section{Finite-element model of crack opening}

The present study considers the period of crack propagation (opening) that is associated with relatively advanced stages of rebar corrosion. It is expected that conditions at the bar surface along the length of a RC element become more homogeneous after cracking of the concrete cover and bar exposure to the 


\begin{tabular}{|c|c|c|c|c|c|c|c|c|}
\hline Series & Specimen & $c_{1}: m m$ & $\begin{array}{c}c_{2} \text { or } s: \\
\mathrm{mm}\end{array}$ & $\begin{array}{l}\text { Mean concrete } \\
\text { compressive } \\
\text { strength: MPa }\end{array}$ & $\begin{array}{c}\text { Mean concrete } \\
\text { tensile strength: } \\
\text { MPa }\end{array}$ & $\begin{array}{c}\text { Bar } \\
\text { diameter: } \\
\text { mm }\end{array}$ & $\begin{array}{l}i_{\text {corr(exp) }}: \\
\mu \mathrm{A} / \mathrm{cm}^{2}\end{array}$ & $\begin{array}{l}\text { Time to crack } \\
\text { initiation: } h\end{array}$ \\
\hline \multirow[t]{8}{*}{\|\|$^{*}$} & $20-16$ e & 20 & 50 & $23 \cdot 4$ & $2 \cdot 4$ & 16 & 196 & 19 \\
\hline & $20-16 i$ & 20 & 64 & $23 \cdot 4$ & $2 \cdot 4$ & 16 & 172 & 19 \\
\hline & $10-16 \mathrm{e}$ & 10 & 50 & $23 \cdot 4$ & $2 \cdot 4$ & 16 & 182 & 19 \\
\hline & 10-16i & 10 & 64 & $23 \cdot 4$ & $2 \cdot 4$ & 16 & 163 & 19 \\
\hline & $20-27 e$ & 20 & 50 & $23 \cdot 4$ & $2 \cdot 4$ & 27 & 147 & 19 \\
\hline & $20-27 i$ & 20 & 62 & $23 \cdot 4$ & $2 \cdot 4$ & 27 & 131 & 19 \\
\hline & $10-27 e$ & 10 & 50 & $23 \cdot 4$ & $2 \cdot 4$ & 27 & 116 & 19 \\
\hline & $10-27 i$ & 10 & 62 & $23 \cdot 4$ & $2 \cdot 4$ & 27 & 117 & 19 \\
\hline \multirow[t]{2}{*}{ IV† } & $20-16$ e & 20 & 50 & $8 \cdot 0$ & $1 \cdot 3$ & 16 & 140 & 72 \\
\hline & $10-16$ e & 10 & 50 & 8.0 & $1 \cdot 3$ & 16 & 154 & 42 \\
\hline \multirow[t]{8}{*}{ V† } & $40-16$ e & 40 & 42 & $40 \cdot 0$ & $3 \cdot 79$ & 16 & 98 & 48 \\
\hline & $40-16 i$ & 40 & 70 & $40 \cdot 0$ & $3 \cdot 79$ & 16 & 96 & 48 \\
\hline & $30-16 i$ & 30 & 70 & $40 \cdot 0$ & $3 \cdot 79$ & 16 & 92 & 48 \\
\hline & $20-16$ e & 20 & 42 & $40 \cdot 0$ & $3 \cdot 79$ & 16 & 92 & 48 \\
\hline & $20-16 i$ & 20 & 77 & $40 \cdot 0$ & $3 \cdot 79$ & 16 & 91 & 48 \\
\hline & $10-16 i$ & 10 & 77 & $40 \cdot 0$ & $3 \cdot 79$ & 16 & 93 & 48 \\
\hline & $20-27 i$ & 20 & 72 & $40 \cdot 0$ & $3 \cdot 79$ & 27 & 97 & 48 \\
\hline & $10-27 i$ & 10 & 72 & $40 \cdot 0$ & 3.79 & 27 & 97 & 48 \\
\hline
\end{tabular}

* Average of two rebars

† Single rebars: i, internal (corner) bars; e, = external (middle) bars

Table 1. Summary of experimental parameters for RC specimens, measured corrosion rates and times to crack initiation (adapted from Mullard and Stewart (2011))

atmosphere. Thus, it is assumed that corrosion is uniform along the length of a RC element so that the problem can be solved using a 2D plane strain formulation (i.e. by analysing a plane cross-section normal to the direction of corroding reinforcing bars). It is worth noting that in the accelerated corrosion tests of RC slabs (Mullard and Stewart, 2011) analysed here, although localised (pitting) corrosion was observed, the crack patterns followed those expected from uniform corrosion. Numerical investigation of crack opening in concrete covers was performed using the commercial FE code Abaqus (Hibbitt et al., 2007). Two FE models for simulating corrosion-induced crack opening were first compared.

The first model is non-linear, in which concrete behaviour under tension is described by the cohesive crack model (Hillerborg et al., 1976) while under compression it is assumed to be linearly elastic. The latter assumption is appropriate for modelling corrosion-induced crack initiation and propagation since concrete behaviour in this case is dominated by tensile cracking at low levels of compressive stresses. The concrete model can develop tensile cracks only. The concrete material between cracks is treated as linearly elastic and isotropic. Crack initiation is defined based on the Rankine criterion postulating the formation of a crack normal to the direction of the maximum principal stress when the tensile strength of the concrete is exceeded. The orientation of a crack formed at a point was stored for subsequent calculations. The development of additional cracks in the already cracked continuum was modelled using the fixed orthogonal crack approach, according to which a new crack at the same point can form only in a direction orthogonal to the direction of an existing crack. The tension softening in the direction normal to a crack is described based on the Hillerborg cohesive crack model (Hillerborg et al., 1976), in which a stress-displacement curve is adopted from CEB-FIP model code 1990 (CEB, 1993).

The use of the non-linear model for studying crack propagation is rather time-consuming, since the non-linear problem is solved by an explicit solution scheme. In order to reduce the computation time, an alternative FE model was considered. In this model, concrete is treated as a linear elastic material, while a vertical crack above a corroding reinforcing bar is created by introducing a gap of $9 \times 10^{-6} \mathrm{~mm}$ in the concrete cover - this simulates crack initiation.

In both FE models, the expansion of corrosion products around a corroding reinforcing bar is modelled using a thermal analogy 


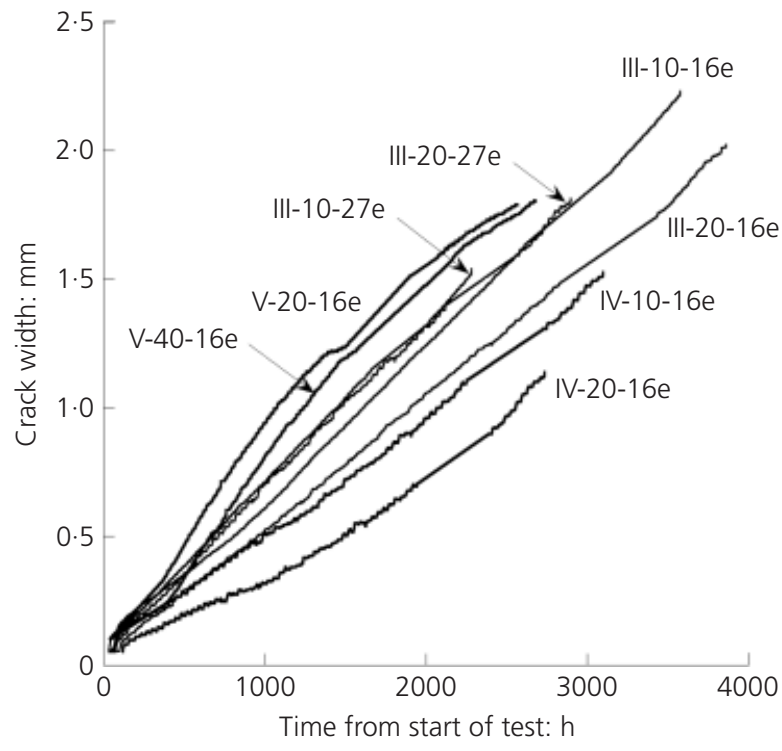

(a)

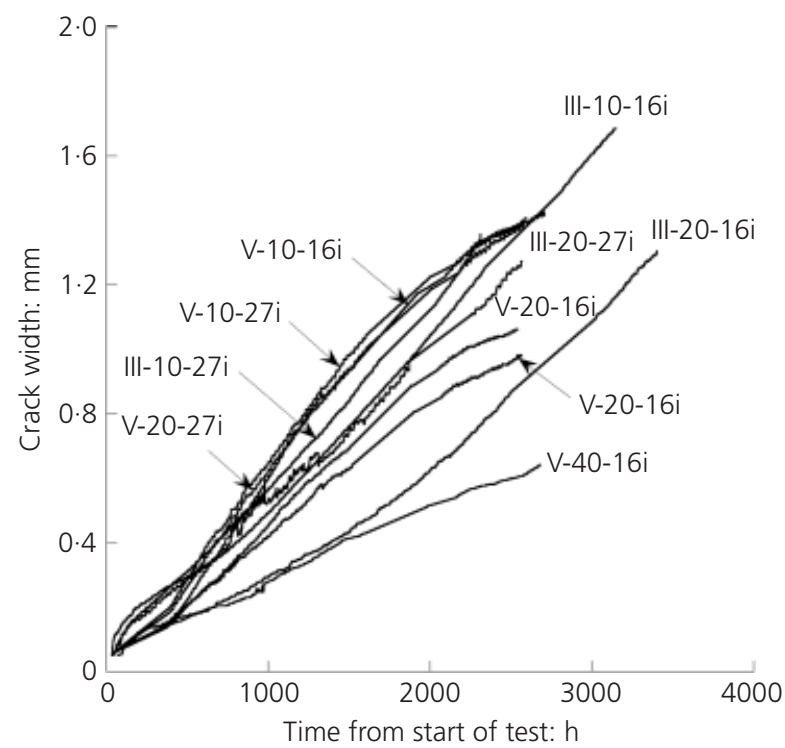

(b)

Figure 2. Test results for crack opening above (a) corner and (b) middle bars from Mullard and Stewart (2011)

(i.e. by increasing the temperature of the rebar, which leads to its thermal expansion). This technique was chosen since other available techniques (e.g. applying internal pressure or radial displacements) can lead to an incorrect prediction of the stress-strain state in the concrete around a corroded reinforcing bar (Chernin and Val, 2011). Four-node bilinear plane strain quadrilateral finite elements with reduced integration and hourglass control were used to represent both the concrete section and reinforcing bars. The penalty contact algorithm was employed to model the interaction (including friction) between a corroded reinforcing bar and concrete (Hibbitt et al., 2007). No other constraints were applied to the reinforcing bars. The following assumptions were adopted in the FE analysis:

(a) diffusion of corrosion products into concrete pores and cracks was not considered

(b) deformability of corrosion products was neglected

(c) mechanical interaction between a reinforcing bar and the surrounding concrete was modelled using the Coulomb friction model with the coefficient of friction equal to $0 \cdot 4$ (Lundgren, 2002).

In addition, two cases representing different locations of a corroded reinforcing bar in a RC section - a corner and middle bar location (Figures 3(a) and 3(b)) - were considered. Typical FE meshes corresponding to the non-linear FE model of a corner bar and the linear FE model of a middle bar with an introduced crack are shown in Figures 3(c) and 3(d). To compare the non-linear and linear FE models, a corner part of the RC slab section (see Figure 3(a)) of specimen IV-10-16e from the tests carried out by Mullard and Stewart (2011) was analysed. The results obtained from the FE analyses along with the test data are shown in Figure 4; the results yielded by the two FE models are quite close. The maximum difference in the corrosion penetration at the same crack width does not exceed $10 \%$ of the experimental value. This means that the process of crack opening can be sufficiently accurately modelled using the computationally more efficient linear elastic model with the initially introduced crack. These results also demonstrate that both FE models significantly overestimate crack width. The main reason for this is that the models do not take into account penetration of a part of corrosion products in concrete pores and cracks. Other possible reasons for the discrepancy between FE and experimental results arising due to the use of a linear FE model with an introduced crack are:

(a) neglecting the random formation nature and complicated geometry of cracks in RC

(b) $2 \mathrm{D}$ simplification of the $3 \mathrm{D}$ process of crack formation and spatial distribution of corrosion products

(c) representation of inhomogeneous concrete using a linear material model

(d) neglecting mechanical behaviour of corrosion products.

Estimation of the difference between the FE models and the test results is considered in detail in the next section.

\section{Amount of corrosion products penetrating concrete cracks}

Figure 4 shows a significant discrepancy between the results yielded by the two FE models and the test data. As mentioned previously, the main cause of this discrepancy is the diffusion of a part of the corrosion products into concrete pores and cracks (dissipation), which is not taken into account by the FE models. According to the findings of an experimental study carried out by Wong et al. (2010), corrosion products at the crack propagation 


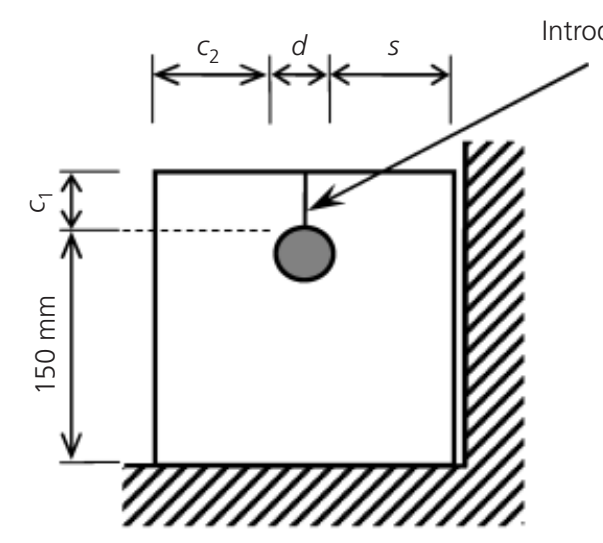

(a)

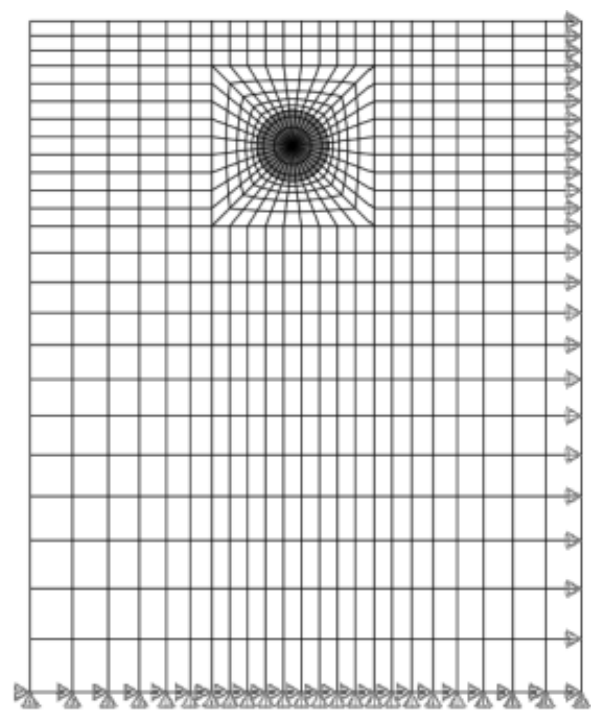

(c)

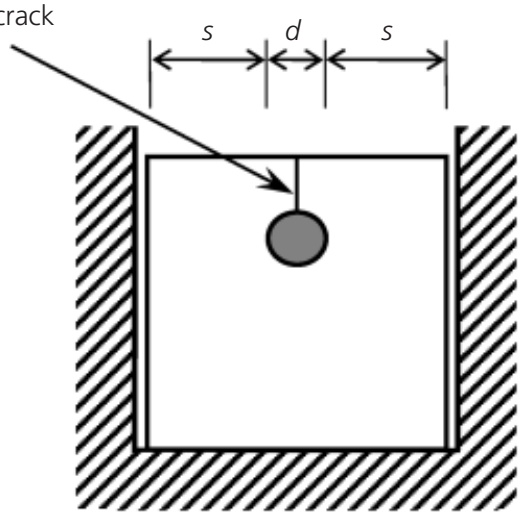

(b)

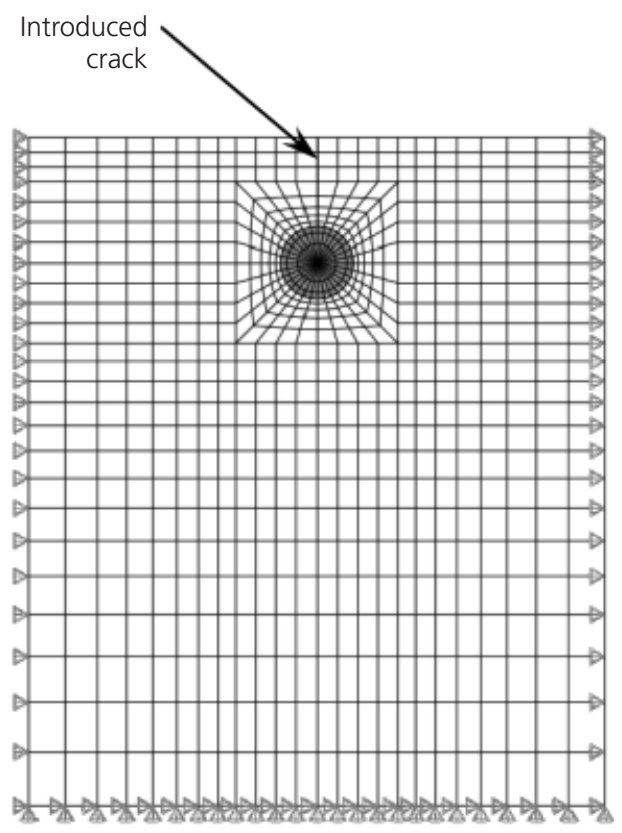

(d)

Figure 3. Segments of RC cross-section with (a) corner rebar and (b) middle rebar and corresponding FE models (c) non-linear and (d) linear with an introduced crack

stage are mainly located in large cracks rather than in concrete pores. Therefore, assuming that corrosion products do not penetrate concrete pores leads to an insignificant overestimation of the amount of corrosion products penetrating concrete cracks. A method for evaluation of this amount is developed. The expansion of corrosion products modelled in the FE analysis represents only a part of corrosion products that accumulate around a corroding reinforcing bar and contribute to the pressure on the surrounding concrete and, subsequently, to crack opening. The corrosion penetration corresponding to this part of the corrosion products is denoted $x_{\mathrm{FEA}}$. The corrosion penetration corresponding to the corrosion products that diffuse into concrete cracks, $x_{\mathrm{cr}}$, can then be found from:
14. $x_{\mathrm{cr}}=x_{\exp }-x_{\mathrm{FEA}}$

where $x_{\exp }$ is the corrosion penetration in a test at which the crack width observed in the test equals the crack width obtained by FE analysis for the corrosion penetration $x_{\mathrm{FEA}}$. The values of $x_{\mathrm{cr}}$ obtained using Equation 14 implicitly account for the influence of the other factors (see the previous section) that contribute to the difference between tests results and those of linear FE analysis with an introduced crack.

In order to estimate $x_{\mathrm{cr}}$, the results of the tests on RC slabs performed by Mullard and Stewart (2011) were used. The results 


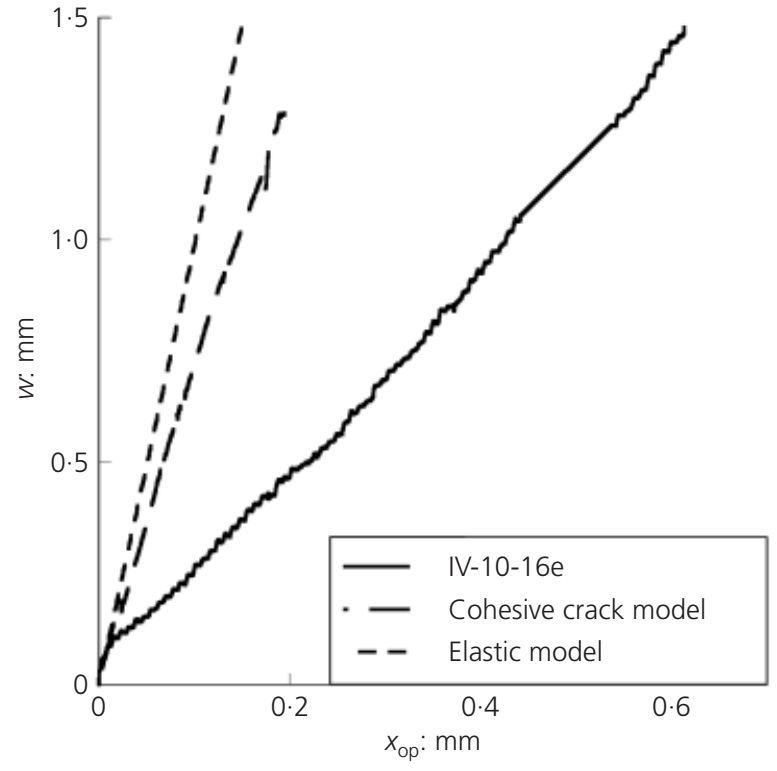

Figure 4. Simulation of test specimen IV-10-16e of Mullard and Stewart (2011)

include data on crack widths above both corner and middle reinforcing bars located at the top of the slabs. Thus, two segments of a RC slab are analysed - one representing the condition of a corner rebar and the other of a middle rebar (Figure 3). In Figure 3, $c_{1}$ and $c_{2}$ are the top and edge concrete covers respectively and $s$ is the half of clear spacing between two adjacent reinforcing bars. Corrosion of a reinforcing bar is simulated by a thermal increase of the rebar diameter $\Delta d$, and the corrosion penetration $x_{\mathrm{FEA}}$ corresponding to $\Delta d$ can be calculated as:

15. $x_{\mathrm{FEA}}=\frac{d}{2}-\left[\left(\frac{d}{2}\right)^{2}-\frac{2 d \Delta d+\Delta d^{2}}{4\left(\alpha_{\mathrm{v}}-1\right)}\right]^{1 / 2}$

where $\alpha_{\mathrm{v}}=3$ is the volumetric expansion of corrosion products (Suda et al., 1993).

In order to find a relationship between $x_{\mathrm{cr}}$ and crack width, $w$, values of $w$ for different $\Delta d$ were first calculated by FE analysis of the two RC slab segments. Results of these analyses were transformed into $x_{\mathrm{FEA}}-w$ relationships using Equation 15, which were then substituted into Equation 14 along with $x_{\exp }-w$ relationships obtained from the experimental data shown in Figure 2. The resulting $x_{\mathrm{cr}}-w$ relationships for the corner and middle rebar locations are shown in Figures 5(a) and 5(b) respectively. Note that the curves presented in Figure 5 were estimated at discrete points based on the test results (i.e. values of $x_{\mathrm{cr}}$ depend directly on the experimentally measured crack widths given in Figure 2). Since the experimental results are not

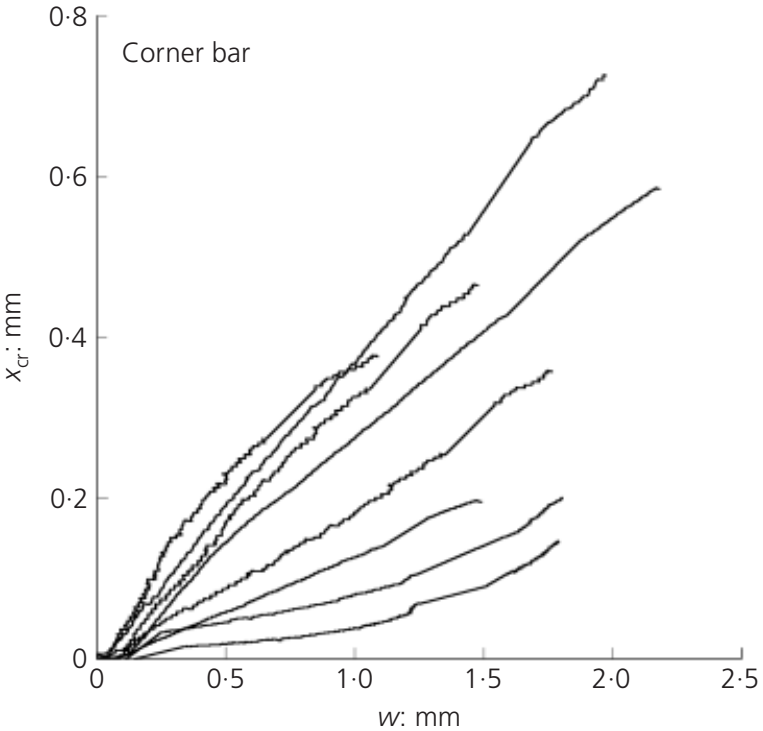

(a)

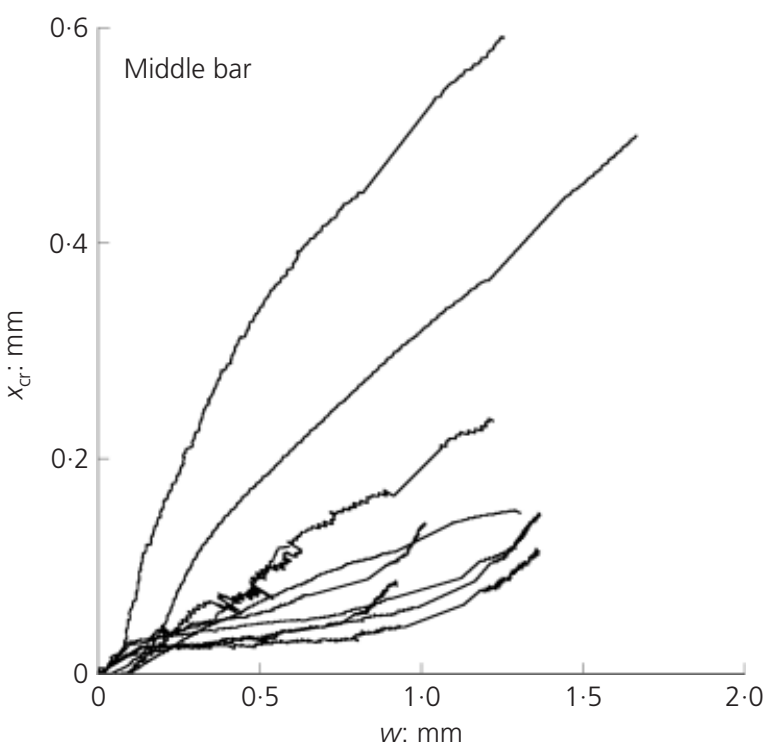

(b)

Figure 5. $x_{\mathrm{cr}}$ versus $w$ for $(\mathrm{a})$ corner and (b) middle bars obtained on the basis of the results of Mullard and Stewart (2011)

smooth, the curves in Figure 5 are not smooth either. It should also be noted that the $x_{\mathrm{cr}}-w$ relationships in Figure 5 do not account for corrosion products penetrating into concrete pores and microcracks before crack initiation.

If a linear relationship is assumed between $x_{\mathrm{cr}}$ and $w$, then

16. $x_{\mathrm{cr}}=B\left(w-w_{\mathrm{i}}\right)$

where $B$ is the rate of penetration of corrosion products into opening cracks and $w_{\mathrm{i}}(=0.05$ according to Andrade et al. 
(1993)) is the crack width at the time of crack initiation. The latter is introduced into Equation 16 in order to ensure that $x_{\mathrm{cr}}=0$ at the time of crack initiation.

Generally, it is expected that the $x_{\mathrm{cr}}-w$ relationships may depend on the RC section geometry ( $c / d$ ratio, bar spacing), rebar location (corner or middle) and material properties of concrete. However, the available experimental data (Mullard and Stewart, 2011) are only sufficient to analyse the dependency between the $c / d$ ratio and $B$. As shown in Figure 6, there is considerable scatter of the results, which does not indicate any relation between $B$ and $c / d$. Thus, only mean values of $B$ were estimated for different locations of a reinforcing bar: 0.239 for a corner rebar and 0.177 for a middle rebar. The lower penetration rate for middle rebars can probably be explained by additional confinement (compared to corner rebars) provided by the surrounding concrete, which leads to reduction of the penetration rate of corrosion products into cracks.

\section{Relationship between corrosion penetration and crack width}

With the relationship between the amount of corrosion products diffusing into concrete cracks and the crack width established (Equation 16), in order to determine the crack width corresponding to a certain corrosion penetration or vice versa, a relationship between $x_{\mathrm{FEA}}$ and $w$ is needed. For a particular RC cross-section this relationship can be found in principle by FE analysis, as shown in the previous section. However, this is relatively time consuming and requires the use of software for FE analysis. In the following, $x_{\mathrm{FEA}}-w$ relationships that take into account crosssection geometry (i.e. thickness of the concrete cover, spacing between reinforcing bars and their location) are derived using the

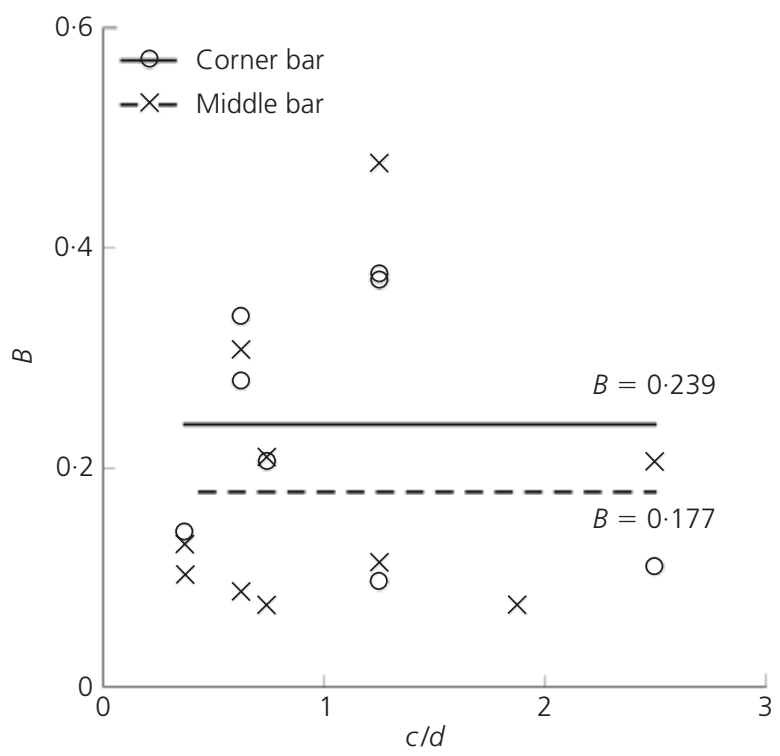

Figure 6 . Rate of penetration of corrosion products into opening cracks $B$ versus $c / d$ for corner and middle bars results of FE analyses. In order to reduce computation time, the linear FE model described previously is employed. This means that any influence of concrete strength on crack opening cannot be taken into account. However, it will be partially accounted for later when the limits of applicability of the derived relationships will be determined using the non-linear FE model. It was also checked that the modulus of elasticity of concrete has an insignificant influence on crack width.

The segments of a RC slab cross-section shown in Figure 3, which represent conditions of a corner and middle reinforcing bars, are analysed. The geometric parameters in Figure 3 vary as follows: $c_{1}=10-60 \mathrm{~mm}, c_{2}=10-100 \mathrm{~mm}$ and $d=10-27 \mathrm{~mm}$. In addition, it was found that the parameter $s$ in the corner segment (Figure 3(a)) has an insignificant influence on crack width development. In order to decrease the number of possible combinations of geometric parameters, this parameter was set equal to $100 \mathrm{~mm}$ in all calculations of the corner segment. Further in the analysis, the parameter $s$ in the middle segment (Figure $3(\mathrm{~b})$ ) is denoted as $c_{2}$ in order to simplify the notation. In the analysis, concrete modulus of elasticity of $E_{\mathrm{c}}=20 \mathrm{GPa}$ and Poisson's ratio of $v_{\mathrm{c}}=0.2$ were used. The analyses were performed for $w \leqslant 2 \mathrm{~mm}$, which was chosen as the upper limit because excessive cracking and delamination of the concrete cover usually occurs before the crack width reaches $2 \mathrm{~mm}$.

A form of the $x_{\mathrm{FEA}}-w$ relationship similar to Equation 16 was adopted:

17. $x_{\mathrm{FEA}}=A\left(w-w_{\mathrm{i}}\right)$

where $A$ represents the rate of accumulation of corrosion products around a corroding rebar (only these corrosion products cause crack opening). A multi-parametric regression analysis was performed in order to evaluate approximately the coefficient $A$. For this purpose, decomposition of $A$ into a polynomial series in terms of the parameters affecting crack opening (i.e. $c_{1}, c_{2}$ and d) was used:

18.

$$
A \cong A_{\text {ap }}\left(c_{1}, c_{2}, d\right)=\sum_{i=0}^{n} \sum_{j=0}^{n} \sum_{k=0}^{n} a_{(i, j, k)} c_{1}^{i} c_{2}^{j} d^{k}
$$

where $a_{(i, j, k)}$ are coefficients, $n$ is the degree of the polynomial series and subscript ap means approximated. The degree $n$ defines the accuracy of the approximation - the larger $n$, the better the approximation. $A_{\text {ap }}$ can be expressed in matrix form as:

19. $A_{\mathrm{ap}}\left(c_{1}, c_{2}, d\right)=\boldsymbol{m} \cdot \boldsymbol{a}_{\mathrm{ap}}$

where the vector of variables $\boldsymbol{m}$ and the vector of coefficients $\boldsymbol{a}_{\text {ap }}$ are formulated as: 


$$
\begin{aligned}
& \quad \boldsymbol{m}= {\left[1,\left(c_{1}, c_{2}, d\right)_{1 \mathrm{~d}},\left(c_{1}^{2}, c_{2}^{2}, d^{2}, \ldots, c_{2} d\right)_{2 \mathrm{~d}},\right.} \\
&\text { 20. } \left.\quad\left(c_{1}^{3}, c_{2}^{3}, d^{3}, \ldots, c_{1} c_{2} d\right)_{3 \mathrm{~d}}, \ldots\right]
\end{aligned}
$$$$
\boldsymbol{a}_{\mathrm{ap}}=\left[a_{(0,0,0)},\left(a_{(1,0,0)}, a_{(0,1,0)}, a_{(0,0,1)}\right)_{1 \mathrm{~d}},\right.
$$$$
21 .
$$$$
\left.\left(a_{(2,0,0)}, \ldots, a_{(0,1,1)}\right)_{2 \mathrm{~d}},\left(a_{(3,0,0)}, \ldots, a_{(1,1,1)}\right)_{3 \mathrm{~d}}, \ldots\right]
$$

in which subscripts $1 \mathrm{~d}, 2 \mathrm{~d}$ and $3 \mathrm{~d}$ mean polynomial terms of first, second and third order, respectively.

\section{Algorithm for calculation of $X_{\mathrm{FEA}}-W$ relationships}

In order to derive the $x_{\mathrm{FEA}}-w$ relationship for a corner reinforcing bar, the following steps of multi-parametric regression analysis were carried out.

(a) $60 \mathrm{FE}$ simulations of the corner segment (Figure 3(a)) with different values of the geometrical parameters $c_{1}, c_{2}$ and $d$ were performed.

(b) The vector of variables $\boldsymbol{m}$ was calculated for every FE simulation and the matrix $\boldsymbol{M}$ is built from vectors $\boldsymbol{m}$ as:

$$
\text { 22. } \boldsymbol{M}=\left[\boldsymbol{m}_{1}, \boldsymbol{m}_{2}, \boldsymbol{m}_{3}, \ldots, \boldsymbol{m}_{60}\right]^{\mathrm{T}}
$$

where the subscript denotes the number of the FE simulation.

(c) Values of $A$ were calculated for every FE simulation using a linear regression analysis of the $x_{\mathrm{FEA}}-w$ relationship (Equation 17) and the vector $\boldsymbol{a}_{\mathrm{FEA}}$ built as:

$$
\text { 23. } \boldsymbol{a}_{\text {ap }}=\left[A_{1}, A_{2}, A_{3}, \ldots, A_{60}\right]
$$

The vector $\boldsymbol{a}_{\mathrm{ap}}$ was found by solving the least-squares problem:

\section{Minimize $\left\|\boldsymbol{M} \boldsymbol{a}_{\mathrm{ap}}-\boldsymbol{a}_{\mathrm{FEA}}\right\|$}

(d) Finally, approximate values of $A_{\text {ap }}$ can be calculated with a required accuracy for any combination of $c_{1}, c_{2}$ and $d$ using Equation 19 so that the $x_{\mathrm{FEA}}-w$ relationship (Equation 17) is determined with $A$ replaced by $A_{\text {ap }}$.

The same algorithm was applied to find the $x_{\mathrm{FEA}}-w$ relationship for a middle bar; in this case $70 \mathrm{FE}$ simulations of the middle segment (Figure 3(b)) were performed with different values of

\begin{tabular}{|c|c|c|}
\hline \multirow{2}{*}{$\begin{array}{l}\text { Components } \\
\text { of vector } m\end{array}$} & \multicolumn{2}{|c|}{$a_{(i, j, k)}$} \\
\hline & Corner bar & Middle bar \\
\hline 1 & $9.87 \times 10^{-2}$ & 0.410 \\
\hline$C_{1}$ & $-2.36 \times 10^{-3}$ & $2.90 \times 10^{-2}$ \\
\hline$C_{2}$ & $2.61 \times 10^{-3}$ & $-2.75 \times 10^{-2}$ \\
\hline$d$ & $-5.27 \times 10^{-3}$ & $2.07 \times 10^{-2}$ \\
\hline$c_{1}^{2}$ & $-4.27 \times 10^{-6}$ & $5.24 \times 10^{-4}$ \\
\hline$c_{2}^{2}$ & $-2.23 \times 10^{-5}$ & $4.75 \times 10^{-4}$ \\
\hline$d^{2}$ & $3.00 \times 10^{-4}$ & $-7 \cdot 12 \times 10^{-4}$ \\
\hline$c_{1} d$ & $5.27 \times 10^{-5}$ & $-7.96 \times 10^{-4}$ \\
\hline$c_{2} d$ & $-1.17 \times 10^{-4}$ & $8.10 \times 10^{-6}$ \\
\hline$c_{1} C_{2}$ & $5.42 \times 10^{-5}$ & $-6.92 \times 10^{-4}$ \\
\hline$c_{1}^{3}$ & $3.18 \times 10^{-8}$ & $4.60 \times 10^{-7}$ \\
\hline$c_{2}^{3}$ & $1.70 \times 10^{-8}$ & $-2.35 \times 10^{-6}$ \\
\hline$d^{3}$ & $-5 \cdot 11 \times 10^{-6}$ & $5.02 \times 10^{-6}$ \\
\hline$c_{1}^{2} d$ & $1.01 \times 10^{-6}$ & $-1.65 \times 10^{-6}$ \\
\hline$c_{1} d^{2}$ & $-1.16 \times 10^{-6}$ & $1.06 \times 10^{-5}$ \\
\hline$c_{2}^{2} d$ & $5.75 \times 10^{-7}$ & $-1.80 \times 10^{-6}$ \\
\hline$c_{2} d^{2}$ & $2.12 \times 10^{-6}$ & $4.64 \times 10^{-6}$ \\
\hline$c_{1}^{2} c_{2}$ & $-3.90 \times 10^{-7}$ & $-4.90 \times 10^{-6}$ \\
\hline$c_{1} c_{2}^{2}$ & $1.28 \times 10^{-7}$ & $4.82 \times 10^{-6}$ \\
\hline$c_{1} c_{2} d$ & $-1.47 \times 10^{-6}$ & $3.18 \times 10^{-6}$ \\
\hline
\end{tabular}
$c_{1}, s\left(=c_{2}\right)$ and $d$.

\section{Derived $X_{F E A}-W$ relationships}

Components of the vector $\boldsymbol{a}_{\text {ap }}$ (Equation 21) calculated using thirddegree polynomials are presented in Table 2 . The mean error
Table 2. The components of the vector $a_{\mathrm{ap}}$ (third-degree polynomials)

associated with approximation of $A$ by the third-degree polynomial $\boldsymbol{a}_{\text {ap }}$ is less than $1 \%$ for the corner bar segment and $6 \%$ for the middle bar segment. A disadvantage of using the third-degree polynomials is that the obtained expressions for $A_{\text {ap }}$ are rather complicated. Simpler expressions for $A_{\text {ap }}$ can be obtained using the first-degree polynomials. For the corner bar segment:

$$
\begin{aligned}
A_{\text {ap }}= & \left(69.493-0.498 c_{1}\right. \\
& \left.+0.9326 c_{2}-0.399 d\right) \times 10^{-3}
\end{aligned}
$$$$
25 .
$$

and for the middle bar:

$$
\begin{aligned}
A_{\mathrm{ap}}= & \left(276.633+6.234 c_{1}-2.026 c_{2}\right. \\
& -3.723 d) \times 10^{-3}
\end{aligned}
$$$$
26 .
$$

where $c_{1}, c_{2}$ and $d$ are in mm. Obviously, this approximation is less accurate; the mean error in this case increases up to $6 \%$ for the corner bar segment and $18 \%$ for the middle bar segment.

Range of applicability of the $X_{F E A}-W$ relationships The linear FE model with an introduced vertical crack simulates only one mode of failure of the concrete cover, namely cracking 
above a reinforcing bar. Other possible failure modes of the concrete cover such as delamination and spalling cannot be analysed, since the model cannot simulate crack initiation in concrete. Thus, the range of applicability of the model needs to be assessed. For this purpose, a part of a RC slab cross-section with two reinforcing bars (see Figure 7) was analysed using the non-linear FE model described previously. The material properties used in the analyses were: $f_{\mathrm{ct}}=3.0 \mathrm{MPa}, E_{\mathrm{c}, \mathrm{ef}}=20 \mathrm{GPa}$, $v=0 \cdot 2$. Values of the geometric parameters of the section in Figure 7 vary in the range: $c_{1}=20-60 \mathrm{~mm}, c_{2}=25-125 \mathrm{~mm}$ and $d=16-24 \mathrm{~mm}$. The clear bar spacing is assumed to be equal to $2 c_{2}$. More than 50 non-linear FE simulations of the RC section with different combinations of $c_{1}, c_{2}$ and $d$ were performed. Four types of cover failure (see Figure 7) observed in the tests and relevant to both corner and middle bar locations were obtained: type 1 and 2 failures are cracking above the corner and middle bars, respectively; type 3 is delamination between the bars; type 4 is spalling of the section corner. The influence of $c_{1}, c_{2}$ and $d$ on the type of cover failure was studied and the sequence in the development of the failure types was traced depending on $x_{\text {FEA }}$. Results of the FE analyses are presented in Figure 8.

The types of cover failure relevant to the corner rebar are considered first. The results in Figure 8(a) show that for $c_{2} / c_{1} \geqslant 1 \cdot 1$, cracking of the concrete cover above the corner bar occurs before delamination between the bars. However, for $c_{2} / c_{1}<1 \cdot 1$, delamination occurs before cracking. Spalling of the concrete corner is the last to develop. Linear regression analysis of the obtained data resulted in the following.

For type 1 (cracking above the corner bar):

27. $x_{\mathrm{FEA}}=-0 \cdot 1788\left(c_{2} / c_{1}\right)+4 \cdot 5651\left(R^{2}=0 \cdot 9121\right)$

For type 3 (delamination between the bars):

28. $x_{\mathrm{FEA}}=4 \cdot 8604\left(c_{2} / c_{1}\right)+0.5066\left(R^{2}=0.9747\right)$

For type 4 (spalling of the section corner):

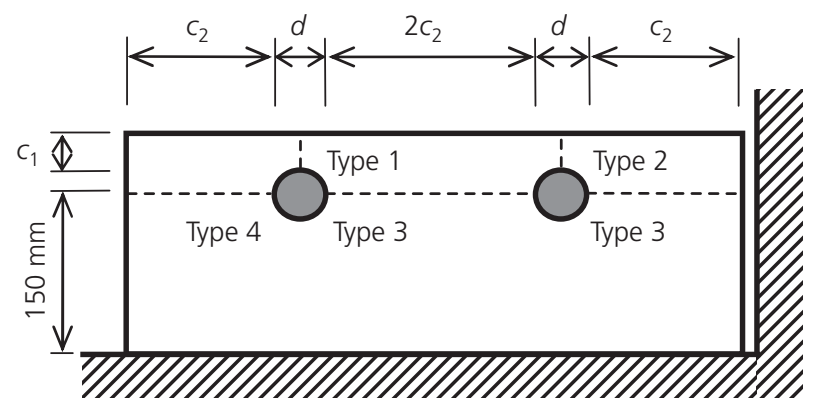

Figure 7. Section of RC slab with two reinforcing bars

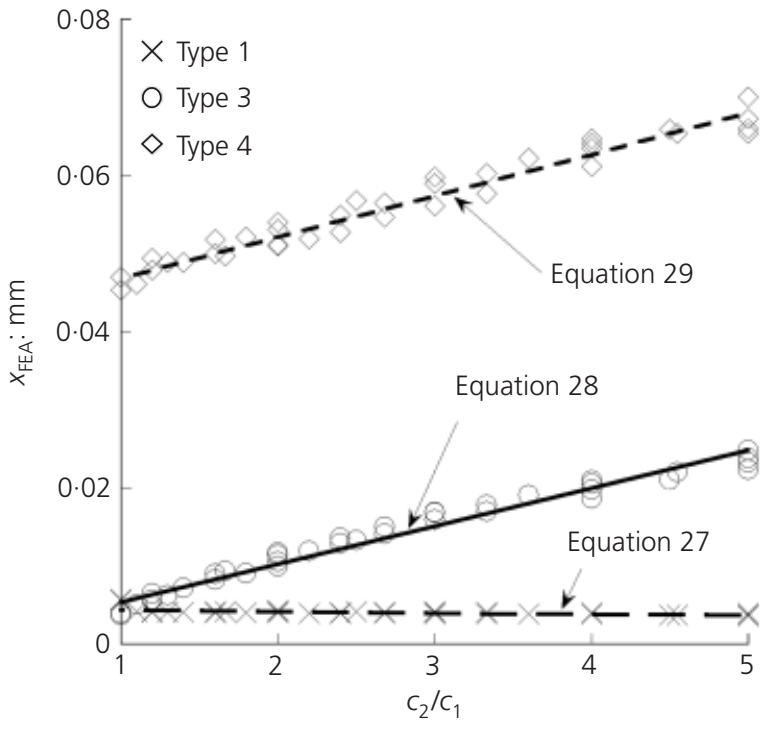

(a)

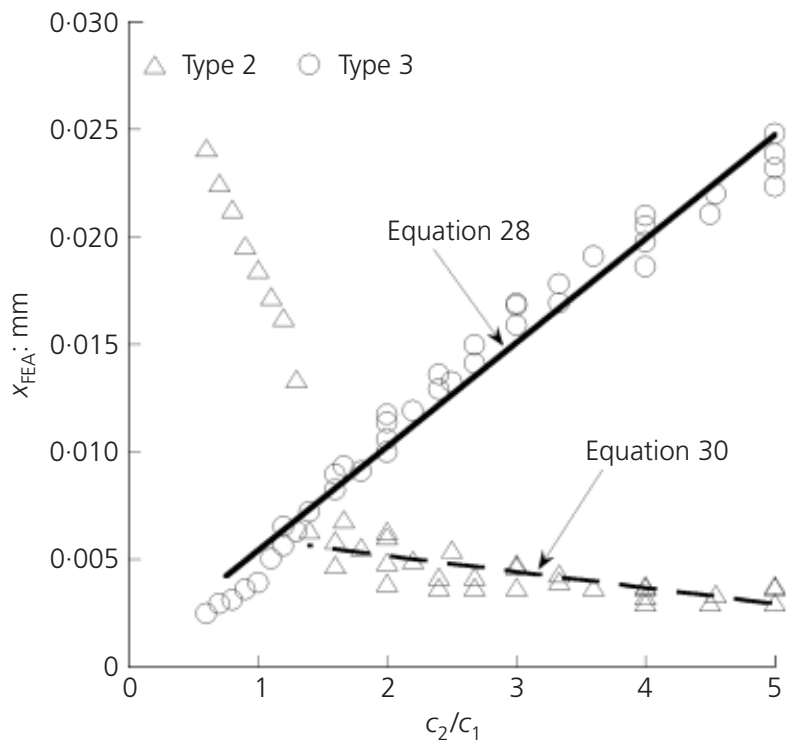

(b)

Figure 8. Effect of $c_{2} / c_{1}$ on $X_{F E A}$ for (a) corner and (b) middle bars

29. $x_{\mathrm{FEA}}=5 \cdot 253\left(c_{2} / c_{1}\right)+41.797\left(\mathrm{R}^{2}=0 \cdot 9602\right)$

where $R^{2}$ is the coefficient of determination. Figure 8(a) shows that the $x_{\mathrm{FEA}}-w$ relationship (Equation 17) proposed for the corner bar can be used when $c_{2} / c_{1} \geqslant 1 \cdot 1$ and until $x_{\mathrm{FEA}}$ does not exceed a value given by Equation 28. The fact that spalling of the section corner occurs last can be explained by the development of a crack (inclined or vertical) beneath the corner rebar. This leads to a release of pressure on the corner of the concrete section and, as a result, delays spalling. It should be noted that the development of similar cracks beneath the corner bars and delamination of concrete covers between bars without any corner spalling were observed in tests (e.g. Vu et al., 2005). 
The types of failure of the concrete cover around the middle rebar (see Figure 7), namely cracking above the bar (type 2) and delamination between the bars (type 3), are now analysed. Linear regression analysis of cracking above the middle bar yields

30. $x_{\mathrm{FEA}}=-0.7579\left(c_{2} / c_{1}\right)+6.7155\left(R^{2}=0.6537\right)$

Figure 8 (b) shows that delamination occurs before cracking above the middle bar when $c_{2} / c_{1}<1.4$ and the proposed $x_{\mathrm{FEA}}-w$ relationship (Equation 17) is then inapplicable. The $x_{\mathrm{FEA}}-w$ relationship can be used when $c_{2} / c_{1} \geqslant 1.4$ and until $x_{\mathrm{FEA}}$ does not exceed a limit value defined by Equation 28 .

\section{Use of derived relationships for prediction of crack width or corrosion penetration}

The relationships derived in this paper can be used to evaluate the crack width given the corrosion penetration or vice versa. In the latter case, corrosion penetration since crack initiation in the concrete cover can be estimated as:

31. $x_{\mathrm{op}}=x_{\mathrm{FEA}}+x_{\mathrm{cr}}=(A+B)\left(w-w_{\mathrm{i}}\right)$

where $x_{\mathrm{cr}}$ and $x_{\mathrm{FEA}}$ are evaluated using Equations 16 and 17 . Since Equation 31 is linear it can be easily inverted for evaluation of $w$ when $x_{\mathrm{op}}$ is known.

It is important to note that the model proposed in this paper, in particular the coefficient $B$ in Equation 31, was derived using the results of tests with accelerated corrosion. Consequently, use of the model to predict crack widths in actual RC structures, in which corrosion rates are much lower (i.e. $1-3 \mu \mathrm{A} / \mathrm{cm}^{2}$ ), may require correction of the results if the rate of loading correction factor $k_{\mathrm{R}}$ proposed by $\mathrm{Vu}$ et al. (2005) is deemed appropriate. This can be done in accordance with Equation 13 by multiplying the coefficient $B$ in Equation 31 by $k_{\mathrm{R}}$ given by Equation 11 where $i_{\text {corr(exp) }}=100 \mu \mathrm{A} / \mathrm{cm}^{2}$.

Validation of the proposed model (i.e. Equation 31) is complicated by a lack of sufficient experimental data. Since the proposed model distinguishes between corner and middle bar locations, separate sets of test data for these locations are needed. This kind of test data has only been reported by Mullard and Stewart (2011) and has already been used in this paper to estimate the amount of corrosion products penetrating cracks. However, in order to illustrate the different relationships for corner and middle bars, a comparison of the proposed model (third-degree polynomial approximation) with the Mullard and Stewart (2011) data is presented in Figure 9. A set of experimental data obtained by Vu et al. (2005), which was not used in the estimation of the relationships for $x_{\mathrm{cr}}$, was employed for additional validation of the model. Vu et al. did not separate their data for corner and middle bars and reported only averaged data for all bars (two corner and two middle bars) in a RC slab. Thus,

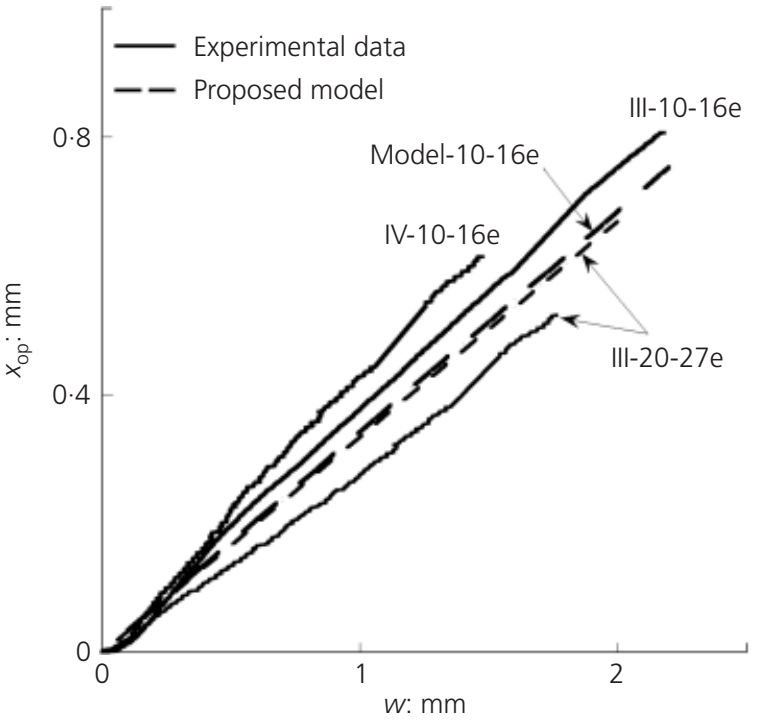

(a)

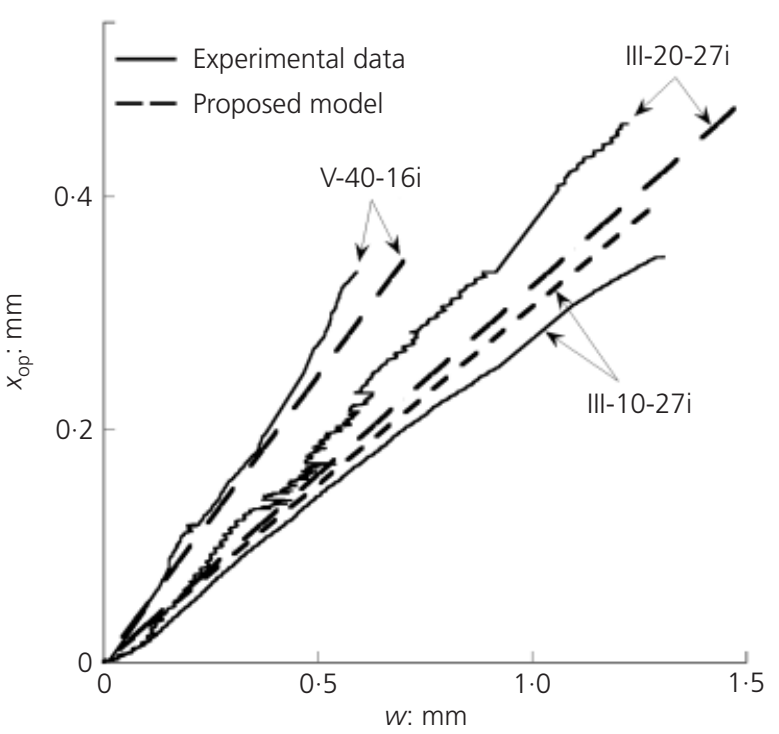

(b)

Figure 9. $x_{\text {op }}$ versus $w$ for $(a)$ corner and (b) middle bars: proposed model compared with experimental data of Mullard and Stewart (2011)

in order to provide a comparison with these results, Equation 31 was also averaged:

$$
x_{\mathrm{op}}=\left(\frac{A_{\text {corner }}+A_{\text {middle }}}{2}+\frac{B_{\text {corner }}+B_{\text {middle }}}{2}\right)\left(w-w_{\mathrm{i}}\right)
$$

The comparison is shown in Figure 10. Good agreement between the model predictions and the test data was found in nearly all cases presented in Figures 9 and 10, but in Figure 10(b) the proposed model noticeably overestimates the experimental results. 
Prediction of cover crack propagation in

RC structures caused by corrosion

Chernin, Val and Stewart

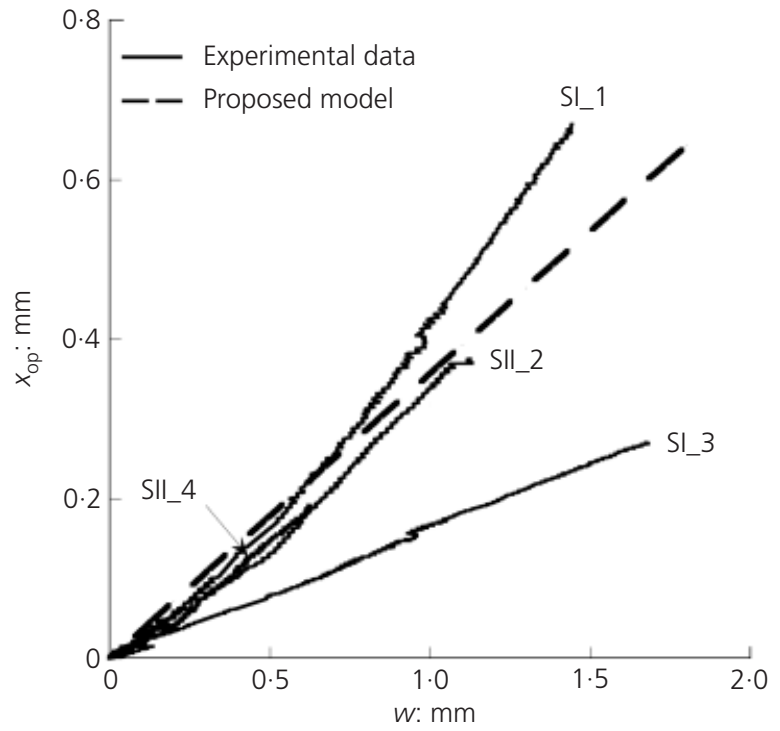

(a)

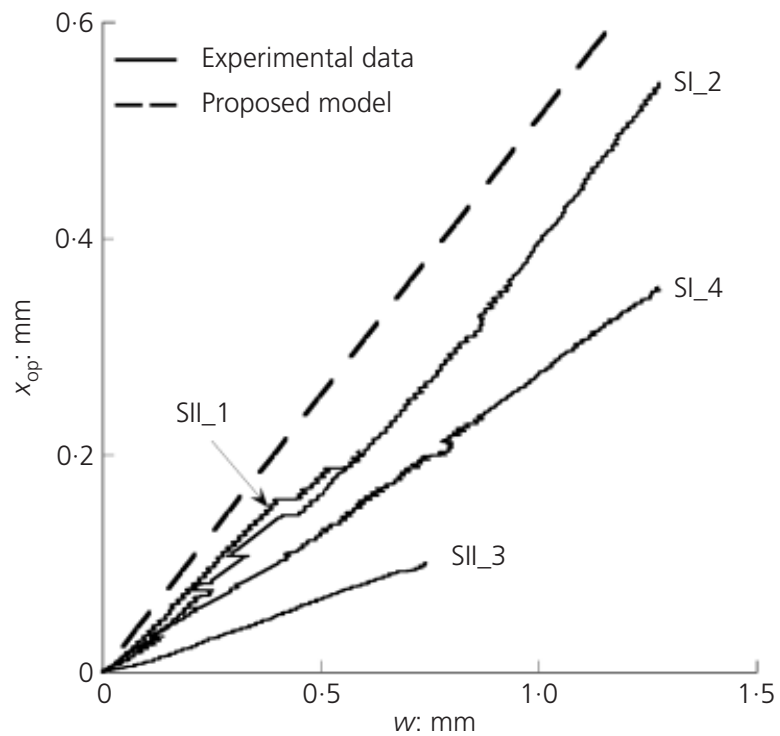

(b)

Figure 10. $x_{\mathrm{op}}$ versus $w$ for specimens with (a) $c=25 \mathrm{~mm}$ and (b) $\mathrm{c}=50 \mathrm{~mm}$ : proposed model compared with experimental data of Vu et al. (2005)

The total corrosion penetration since corrosion initiation, $x_{\text {tot }}$, can then be calculated as:

32. $x_{\mathrm{tot}}=x_{\mathrm{init}}+x_{\mathrm{op}}$

where $x_{\text {init }}$ is the corrosion penetration at the time of crack initiation, which can be evaluated using Faraday's law if the corrosion rate and the times of corrosion initiation and crack initiation are known, or by employing models for corrosion initiation and crack initiation (e.g. Chernin et al., 2010).

\section{Conclusions}

A critical overview of existing models developed for the prediction of crack width in corroded RC elements has been presented. The loss of rebar radius was divided into two parts depending on the role of corrosion products generated (corrosion products penetrating concrete cracks or those causing crack opening). Initially, a FE model was developed to numerically simulate the process of crack opening in a concrete cover. In the model, concrete is treated as a linear elastic material, a vertical crack is introduced above a reinforcing bar and the thermal analogy method is used to simulate the expansive behaviour of corrosion products. The FE model was then employed to simulate accelerated corrosion tests on RC slabs.

The observed differences between the results of the FE analyses and experimental data are mainly due to penetration of a certain amount of corrosion products into concrete cracks. The amount of corrosion products penetrating concrete cracks was calculated to be $0 \cdot 1-0.4 \mathrm{~mm}$ for a $1.0 \mathrm{~mm}$ crack width. Relationships between the loss of rebar radius (corresponding to corrosion products penetrating concrete cracks) and crack width were derived for different locations of reinforcing bars. It was found that the amount of corrosion products entering concrete cracks is relatively insensitive to $c / d$ ratio, but is sensitive to rebar location.

The influence of parameters such as reinforcing bar diameter, thickness of top and edge concrete covers, bar spacing and reinforcing bar location on crack width was also investigated. Relationships between the loss of rebar radius and crack width were derived for different locations of reinforcing bars using multiparametric regression analysis. A non-linear FE analysis using a more sophisticated material model of concrete was employed to establish the limits of applicability of these relationships. It is important to note that the method for evaluation of the level of rebar corrosion presented in this paper was obtained using only a limited set of experimental data. Further experimental and analytical research is thus needed.

\section{REFERENCES}

Alonso C, Andrade C, Rodriguez J and Diez JM (1998) Factors controlling cracking of concrete affected by reinforcement corrosion. Materials and Structures 31(211): 435-441.

Andrade C, Alonso C and Molina FJ (1993) Cover cracking as a function of bar corrosion: Part 1 - Experimental test. Materials and Structures 26(8): 453-464.

Cabrera JG (1996) Deterioration of concrete due to reinforcement steel corrosion. Cement \& Concrete Composites 18(1): 47-59.

CEB (Comité Euro-International du Béton) (1993) CEB-FIP Model Code 1990. Thomas Telford, London.

Chernin L and Val DV (2011) Prediction of corrosion-induced cover cracking in reinforced concrete structures. Construction 
and Building Materials 25(4): 1854-1869. doi: 10.1016/ j.conbuildmat.2010.11.074.

Chernin L, Val DV and Volokh K (2010) Analytical modelling of concrete cover cracking caused by corrosion of reinforcement. Materials and Structures 43(4): $543-556$.

Dagher HJ and Kulendran S (1992) Finite element modelling of corrosion damage in concrete structures. ACI Structural Journal 89(6): 699-708.

DuraCrete (2000) Probabilistic Performance Based Durability Design of Concrete Structures. European Union Brite EuRam III, Brussels.

El Maaddawy TA and Soudki KA (2003) Effectiveness of impressed current technique to simulate corrosion of steel reinforcement in concrete. Journal of Materials in Civil Engineering 15(1): 41-47.

Hansen EJ and Saouma VE (1999) Numerical simulation of reinforced concrete deterioration: Part II - Steel corrosion and concrete cracking. ACI Materials Journal 96(3): 331-338.

Hibbitt HD, Karlsson BI and Sorensen EP (2007) Abaqus Version 6.7 Documentation. Hibbitt, Karlsson \& Sorensen, Inc., Pawtuchet, RI.

Hillerborg A, Modeer M and Petersson PE (1976) Analysis of crack formation and crack growth in concrete by means of fracture mechanics and finite elements. Cement and Concrete Research 6(6): 773-782.

Jang BS and Oh BH (2010) Effects of non-uniform corrosion on the cracking and service life of reinforced concrete structures. Cement and Concrete Research 40(9): $1441-1450$.

Li Y, Vrouwenvelder T, Wijnants GH and Walraven J (2004) Spatial variability of concrete deterioration and repair strategies. Structural Concrete 5(3): 121-130.

Li CQ, Melchers RE and Zheng JJ (2006) Analytical model for corrosion-induced crack width in reinforced concrete structures. ACI Structural Journal 103(4): 479-487.

Lundgren K (2002) Modelling the effect of corrosion on bond in reinforced concrete. Magazine of Concrete Research 54(3): $165-173$.

Mangat PS and Elgarf MS (1999) Bond characteristics of corroding reinforcement in concrete beams. Materials and Structures 32(2): 89-97.

Maruyama K, Takaoka Y, Shimizu K and Nakada Y (1989) Cracking behavior of concrete due to corrosion of reinforcing bars. Transactions of the Japan Concrete Institute 11: 163170.

Molina FJ, Alonso C and Andrade C (1993) Cover cracking as a function of rebar corrosion: Part 2 - Numerical model. Materials and Structures 26(9): 532-548.

Mullard JA and Stewart MG (2009) Stochastic assessment of the timing and efficiency of maintenance for corroding $\mathrm{RC}$ structures. ASCE Journal of Structural Engineering 135(8): 887-895.

Mullard JA and Stewart MG (2011) Corrosion-induced cover cracking: new test data and predictive models. ACI Structural Journal 108(1): 71-79.

Muñoz A, Andrade C, Torres-Acosta A and Rodríguez J (2007) Relation between crack width and diameter of rebar loss due to corrosion of reinforced concrete members. ECS Transactions 3(13): 29-36.

Rodriguez J, Ortega LM, Casal J and Diez JM (1996) Corrosion of reinforcement and service life of concrete structures. Proceedings of the 7th International Conference on Durability of Building Materials and Components, (Sjöström C (ed.)). E \& FN Spon, London, vol. 1, pp. 117-126.

Saifullah M and Clark LA (1994) Effects of corrosion rate on the bond strength of corroded reinforcement. Proceedings of International Conference on Corrosion and Corrosion Protection of Steel in Concrete, Sheffield (Swamy RN (ed.)) Sheffield Academic Press, Sheffield, pp. 591-602.

Suda K, Misra S and Motohashi K (1993) Corrosion products of reinforcing bars embedded in concrete. Corrosion Science 35(5-8): 1543-1549.

Thoft-Christensen P (2001) What happens with reinforced concrete structures when the reinforcement corrodes? Proceedings of the 2nd International Workshop on Life-Cycle Cost Analysis and Design of Civil Infrastructure Systems, Yamaguchi, Japan, 27-29 September, pp. 293-304.

Thoft-Christensen P (2005) Service life definitions based on corrosion crack width. Proceedings of the 9th International Conference on Structural Safety and Reliability, ICOSSAR'05, Rome (Augusti G, Schuëller GI and Ciampolli M (eds)). Millpress, Rotterdam, CD-Rom.

Thoft-Christensen P, Frandsen HL and Svensson S (2008) Numerical study of corrosion crack opening. Structure and Infrastructure Engineering 4(5): 381-391.

Toongoenthong K and Maekawa K (2005) Simulation of coupled corrosive product formation, migration into crack and propagation in reinforced concrete sections. Journal of Advanced Concrete Technology 3(2): 253-265.

Val DV (2007) Factors affecting life-cycle cost analysis of RC structures in chloride contaminated environments. ASCE Journal of Infrastructure Systems 13(2): 135-143.

Val D and Stewart MG (2009) Reliability assessment of ageing reinforced concrete structures - current situation and future challenges. Structural Engineering International 19(2): 211-219.

Val DV, Chernin L and Stewart MG (2009) Experimental and numerical investigation of corrosion-induced cover cracking in RC structure. ASCE Journal of Structural Engineering 135(4): 376-385.

Vidal T, Castel A and Francois R (2004) Analyzing crack width to predict corrosion in reinforced concrete. Cement and Concrete Research 34(1): 165-174.

Vu K, Stewart MG and Mullard J (2005) Corrosion-induced cracking: Experimental data and predictive models. $A C I$ Structural Journal 102(5): 719-726. 
Wong HS, Zhao YX, Karimi AR, Buenfeld NR and Jin WL (2010) On the penetration of corrosion products from reinforcing steel into concrete due to chloride-induced corrosion. Corrosion Science 52(7): 2469-2480.
Zhang R, Castel A and François R (2010) Concrete cover cracking with reinforcement corrosion of RC beam during chlorideinduced corrosion process. Cement and Concrete Research 40(2): 415-425.

\section{WHAT DO YOU THINK?}

To discuss this paper, please submit up to 500 words to the editor at www.editorialmanager.com/macr by 1 August 2012. Your contribution will be forwarded to the author(s) for a reply and, if considered appropriate by the editorial panel, will be published as a discussion in a future issue of the journal. 